\title{
Período Anterior a Interferência de Plantas Daninhas em Soja: Estudo de Caso com Baixo Estande e Testemunhas Duplas ${ }^{1}$
}

\author{
Period Before Weed Interference in Soybean: a Case-Study Under Low Crop Density and \\ Twofold Checks
}

MESCHEDE, D.K. ${ }^{2}$, OLIVEIRA Jr., R.S. ${ }^{3}$, CONSTANTIN, J. ${ }^{3}$ e SCAPIM, C.A. ${ }^{3}$

\begin{abstract}
RESUMO - Conduziu-se experimento na Fazenda Boa Terra (Quarto Centenário, PR), com o objetivo de avaliar o efeito de diferentes períodos de convivência de Euphorbia heterophylla com a soja, cv. BRS-133, cultivada com baixa densidade de semeadura. Utilizou-se um delineamento em blocos casualizados, com quatro repetições, avaliando-se 11 períodos de convivência da soja com plantas daninhas e testemunhas duplas. Os períodos de convivência consistiram em manter a cultura na presença de plantas daninhas por 5, 12, 19, 26, 33, 40, 47, 54, 61 e 68 dias após a emergência e pelo ciclo todo. Quando da primeira capina, foram determinadas as densidades e a matéria seca de E. heterophylla. Estande e produtividade foram as variáveis que expressaram os maiores prejuízos em função do aumento do período de interferência das plantas daninhas. Utilizando-se testemunhas duplas, o período anterior à interferência (PAI) foi de 11 dias após a emergência, o que indica a necessidade de controle precoce das plantas daninhas. Entre 11 e $68 \mathrm{DAE}$, a interferência imposta pelas plantas daninhas promoveu queda diária de $6,45 \mathrm{~kg} \mathrm{ha}^{-1}$ na produtividade da soja, e durante todo o ciclo o percentual de perda estimado foi de $38 \%$.
\end{abstract}

Palavras-chave: competição, Euphorbia heterophylla, testemunhas duplas.

\begin{abstract}
A field experiment was carried out at Boa Terra Farm (Guarto Centenário, PR) ,to evaluate the effect of different periods of Euphorbia heterophylla interference on low-density soybean (cv. BRS-133). The experiment was carried out in a randomized complete block design, with four replicates and 11 periods of weed interference, by using twofold checks. The periods of interference consisted in keeping the weed interference for 5, 12, 19, 26, 33, 40, 47, 54, 61, 68 days after crop emergence (DAE) or for the whole cycle. At the first weeding, $\mathbf{E}$. heterophylla densities and dry mass were analyzed. Crop stand and yield were the parameters that expressed the most damages due to the increased weed interference period. Using twofold checks, the period before interference was 11 days after emergence (DAE), indicating the need of early weed control. From the $11^{\text {th }}$ to the $68^{\text {th }} D A E$, the interference imposed by weeds promoted daily losses of $6.45 \mathrm{~kg} \mathrm{ha}^{-1}$ in soybean yield. Weed competition for the entire cycle promoted a $38 \%$ decrease in crop yield.
\end{abstract}

Key words: competition, Euphorbia heterophylla, two-fold checks.

\section{INTRODUÇÃO}

No tocante à avaliação da interferência imposta pelas plantas daninhas às culturas, as estimativas de maior importância referem-se ao Período Anterior à Interferência (PAI) e ao Período Total de Prevenção de Interferência (PTPI). Quando PAI < PTPI, define-se outro período importante: o Período Crítico de Prevenção de Interferência (PCPI). O PCPI é,

1 Recebido para publicação em 9.12.2003 e na forma revisada em 18.6.2004.

Apresentado pela primeira autora como parte das exigências para obtenção do título de Mestre em Agronomia no Programa de Pós-Graduação em Agronomia da Universidade Estadual de Maringá - UEM.

2 Eng.-Agrônoma, M.S., Programa de Pós-Graduação em Agronomia da UEM, Bolsista da CAPES. ${ }^{3}$ Professor Adjunto, Departamento de Agronomia da UEM, Av. Colombo 5790, 87020-900 Maringá-PR, Bolsista do CNPq. 
por definição, o período do ciclo durante o qual a convivência da cultura com as plantas daninhas resulta em prejuízo na produtividade da espécie de interesse econômico. Esses períodos têm sido o alvo de inúmeros trabalhos recentes de pesquisa em diferentes culturas (Freitas et al., 2002; Kozlowski , 2002; Kozlowski et al., 2002; Pitelli et al., 2002; Salgado et al., 2002; Kuva et al., 2003; Skóra Neto, 2003).

Na prática, os efeitos da interferência são irreversíveis, não havendo recuperação do desenvolvimento ou da produtividade após a retirada do estresse causado pela presença das plantas daninhas (Kozlowski, 2002; Kozlowski et al., 2002). Dessa forma, em termos de manejo de plantas daninhas, o PAI torna-se o período de maior importância do ciclo cultural, a partir do qual a produtividade é significativamente afetada.

O amendoim-bravo ou leiteiro (Euphorbia heterophylla), juntamente com o picão-preto (Bidens pilosa), a trapoeraba (Commelina benghalensis) e a corda-de-viola (Ipomoea grandifolia), constituem-se nas espécies daninhas de maior importância nos cultivos de verão no Estado do Paraná. Em pesquisa realizada por Adegas (1998) em 79 campos de soja do Estado, concluiu-se que E. heterophylla estava presente em $85 \%$ dos campos amostrados e que, em média, o banco de sementes do solo dessa espécie era de 275 sementes $\mathrm{m}^{-2}$. E. heterophylla é também considerada uma das espécies com maior capacidade de competição com a cultura da soja (Voll et al., 2002).

A capacidade competitiva das plantas daninhas em geral cresce à medida que a capacidade de sombreamento das culturas diminui. Normalmente, o principal fator responsável pelo "fechamento" da cultura e conseqüente sombreamento do solo é a população de plantas da cultura. Para o espaçamento de $0,45 \mathrm{~m}$ entre linhas, a população-padrão há alguns anos era de 18 plantas $\mathrm{m}^{-1}$ (equivalente a um estande de 400 mil plantas ha ${ }^{-1}$ ), a qual foi gradativamente reduzida até atingir 15 plantas $\mathrm{m}^{-1}$ (320 mil plantas ha-1). Esse número de plantas pode variar, ainda, em função do cultivar ou do regime de chuvas durante o período de implantação da cultura. Para locais de maior umidade e maior fertilidade, recomenda-se um estande de 10,8 a 11,7 plantas $\mathrm{m}^{-2}(240$ a 260 mil plantas ha-1) (EMBRAPA, 2002).

$\mathrm{Na}$ maioria dos casos, as áreas experimentais nas quais ensaios de campo são conduzidos são heterogêneas quanto à fertilidade do solo, profundidade de semeadura e infestação de plantas daninhas. Tradicionalmente, nos delineamentos em blocos completos ao acaso utiliza-se uma única testemunha capinada dentro de cada bloco (Fagliari et al., 2002). Em muitos casos, essa prática tem se mostrado ineficaz para promover controle adequado da variabilidade da área experimental, com o conseqüente aumento dos valores das diferenças mínimas significativas utilizadas nos testes de comparação de médias. Velini (1995) propôs o aumento do número de repetições como forma de minimizar o efeito da variabilidade do meio, o que, em alguns casos, é eficaz, mas, em outros, pode implicar o aumento do número de repetições. Ainda assim, em certos casos, mesmo o aumento do número de repetições mostrou-se insuficiente para atingir o controle local adequado (Velini et al., 1995).

Considerando a tradicional desuniformidade da ocorrência das plantas daninhas, essa situação torna-se ainda mais crítica em experimentos de competição. Assim, torna-se difícil que uma única parcela represente de forma adequada a infestação de toda a área. Christoffoleti \& Passini (2000) sugerem que, dessa forma, a colocação de uma testemunha ao lado de cada parcela poderia diminuir o erro causado pela desuniformidade de infestação.

A técnica de testemunhas duplas foi inicialmente proposta para a avaliação da seletividade de herbicidas em cana-de-açúcar (Constantin, 1996). Mais recentemente, foi utilizada também no estudo da seletividade de herbicidas em culturas como alface (Giordani et al., 2000) e soja (Lee, 2001). Consiste no aumento do número de testemunhas dentro de cada repetição, o que corresponde a uma parcela não-tratada ao lado de cada parcela que recebeu o tratamento, mantendo-se todas as testemunhas capinadas durante todo o ciclo. De modo geral, utiliza-se a média das testemunhas duplas como referência da infestação testemunha para cada parcela-tratamento (períodos de convivência). 
Esse tipo de experimento confere maior controle sobre a variabilidade do meio, especialmente quando se utiliza o tradicional delineamento em blocos casualizados, com uma única testemunha por bloco. Pretendese que essa técnica seja, portanto, uma forma alternativa de aferir com maior rigor as diferenças entre tratamentos. Apresenta como desvantagem intrínseca o aumento do número de parcelas a serem avaliadas em cada repetição, o qual será de $2 \mathrm{n}+1$, em que $\mathrm{n}$ representa o número de tratamentos a serem avaliados.

O objetivo deste trabalho foi o de determinar o período anterior à interferência em soja, cv. BRS-133, semeada com baixa densidade, utilizando-se a técnica de testemunhas duplas.

\section{MATERIAL E MÉTODOS}

O experimento foi instalado em condições de campo, na Fazenda Boa Terra, no município de Quarto Centenário, Paraná, no mês de novembro do ano agrícola 99/2000. Os dados relativos à caracterização detalhada da área experimental, assim como das condições ambientais, foram previamente descritos em Meschede et al. (2002). Resumidamente, tratase de uma área de clima subtropical, cujo solo classifica-se como Podzólico Vermelho-Escuro Distrófico, textura argilosa $\left(\mathrm{pH} \mathrm{CaCl}_{2} 5,1\right.$; $19 \mathrm{~g} \mathrm{dm}^{-3}$ de $\mathrm{C}$ orgânico), cultivada há vários anos com a sucessão soja-milho. Com base na análise de solo, a área recebeu uma adubação de $290 \mathrm{~kg} \mathrm{ha}^{-1}$ de superfosfato simples, incorporados com grade, e, na semeadura, utilizaram-se ainda $280 \mathrm{~kg} \mathrm{ha}^{-1}$ do formulado 0-15-20.

O cultivar utilizado foi o BRS-133, o qual semiprecoce, com tendência ao engalhamento, o que lhe confere boa capacidade competitiva (Brighenti et al., 2000). A operação conjunta de adubação e semeadura foi realizada em 23/11/1999, depositando-se 18 sementes por metro linear, previamente inoculadas com micronutrientes e fungicida, à profundidade média de $4 \mathrm{~cm}$, com espaçamento de $0,45 \mathrm{~m}$ entre linhas. Após a emergência, o estande foi corrigido e uniformizado por meio de raleio manual, e a população média em cada unidade experimental foi de 12 plantas por metro linear, o que resultou em 267 mil plantas ha-1 O con- $^{-}$ trole de insetos foi feito três vezes durante o ciclo da cultura com inseticidas piretróides. No final do ciclo foi feita uma aplicação de fungicida, para controle de oídio (Microsphaera diffusa).

Além da infestação natural, antes da semeadura da soja foram distribuídas na área experimental sementes de E. heterophylla, para se obter maior uniformização da densidade da infestante na área e estabelecer uma densidade média de 25 plantas $\mathrm{m}^{-2}$. Foram distribuídos a lanço $33 \mathrm{~g}$ de sementes/parcela, tendo estas um índice de germinação de $7 \%$. Esse procedimento resultou em predominio de E. heterophylla como infestante na área experimental ( $>95 \%$ das plantas daninhas presentes).

O delineamento experimental utilizado foi o de blocos casualizados, com quatro repetições. Em cada repetição, os 11 períodos de convivência com as plantas daninhas foram intercalados com 12 testemunhas duplas adjacentes a cada uma das parcelas de períodos de convivência, totalizando 92 unidades experimentais. Todas as testemunhas, assim como as parcelas com os períodos de convivência, foram dispostas no sentido das linhas de plantio.

Cada unidade experimental foi constituída por dez linhas de soja de quatro metros de comprimento, totalizando $22 \mathrm{~m}^{2}$ (4 x 5,5 m). A área útil para as avaliações compreendeu as seis linhas centrais, desprezando-se o metro inicial e final de cada parcela.

Por ocasião da primeira capina dos tratamentos, realizaram-se avaliações do crescimento da cultura da soja. Dessa forma, as avaliações foram feitas semanalmente, aos 5 , $12,19,26,33,40,47,54,61$ e 68 dias após a emergência (DAE) e na pré-colheita (118 DAE). A correlação entre os períodos de interferência e os respectivos estádios fenológicos de desenvolvimento da cultura está representada na Figura 1. Nas datas predeterminadas, foram avaliados na área útil de cada parcela o estande em três metros lineares, a altura e o número de hastes por planta de soja (15 plantas parcela ${ }^{-1}$ ). Todas as testemunhas duplas foram mantidas no limpo por meio de capinas manuais semanais.

Planta Daninha, Viçosa-MG, v.22, n.2, p.239-246, 2004 


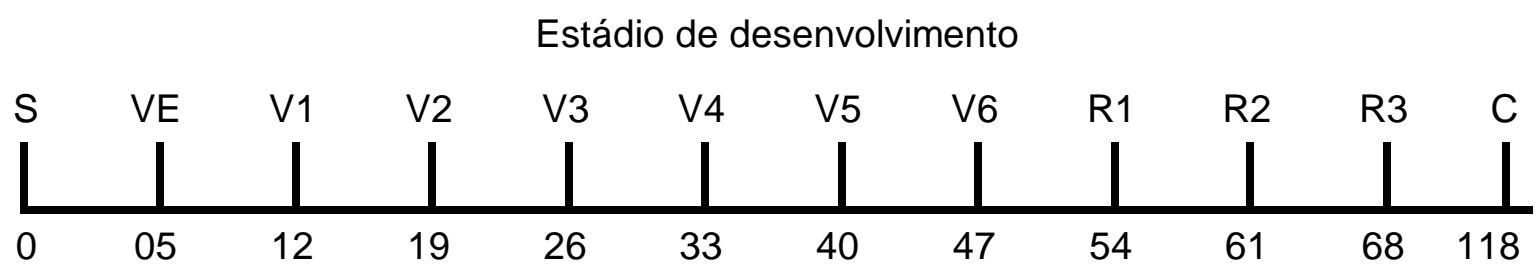

Dias após a emergência

Figura 1 - Resumo esquemático da correspondência entre estádios de desenvolvimento da soja, cv. BRS-133, e períodos de interferência adotados neste experimento. Acima: $\mathrm{S}=$ semeadura; VE = emergência; $\mathrm{Vn}$ ou $\mathrm{Rn}=$ enésimo estádio vegetativo ou reprodutivo; C = colheita. Abaixo = dias após a emergência. Quarto Centenário-PR, 1999/2000.

Para avaliar as densidades de infestação das plantas daninhas, foi utilizado um quadrado de madeira com dimensões de $0,7 \mathrm{x}$ $0,7 \mathrm{~m}$, posicionado duas vezes, aleatoriamente, na área útil de cada parcela. As plantas daninhas presentes na área foram cortadas rente ao solo, identificadas e contadas, sendo, a seguir, mantidas em estufa de circulação mecânica de ar $\left(65^{\circ} \mathrm{C}\right)$, até atingir peso constante. Após a secagem, as plantas foram acondicionadas em sacos plásticos até serem pesadas em balança de precisão, para determinar o peso da matéria seca.

A produtividade da cultura $\left(\mathrm{kg} \mathrm{ha}^{-1}\right)$ foi avaliada por meio da coleta manual de todas as plantas de soja da área útil de cada parcela, as quais foram ensacadas, trilhadas manualmente e pesadas.

Para análise do experimento com testemunhas duplas, empregou-se a análise de covariância. A covariável foi o rendimento oriundo da média das duas testemunhas duplas adjacentes a cada parcela com periodos de convivência de plantas daninhas. A análise de covariância foi realizada no SAEG, por meio do procedimento ANOVAG. O comando a seguir exemplifica a sintaxe utilizada para a análise de variância da produtividade da soja neste experimento:

\section{prod função per cov=prodt}

em que $\operatorname{prod}=$ variável designativa de produtividade da cultura; per $\operatorname{cov}=$ periodos de convivência; e prodt $=$ representação da média do rendimento das duas testemunhas duplas adjacentes (covariável).
Para todas as características avaliadas foram feitas tentativas de ajuste de modelos de regressão polinomiais e não-lineares. No entanto, apenas para estande e número de hastes/planta (modelo logístico) e produtividade (modelo Broken-Stick) foi possivel ajustar equações.

O modelo logístico, expresso pela equação a seguir, apresenta quatro parâmetros, descritos da seguinte forma: o parâmetro " $a_{0}$ " corresponde à assintota mínima; o parâmetro " $\mathrm{b}_{0}$ " é a diferença entre a assintota máxima e a minima; o parâmetro "c c" é o ponto de inflexão da curva, e o parâmetro " $\mathrm{d}_{0}$ " descreve o declive da curva (Ratkowsky, 1990).

$$
Y=\frac{A_{0}+B_{0}}{\left[1\left(X / C_{0}\right) D_{0}\right.}
$$

O modelo Broken Stick (Colwell et al., 1988) é expresso na forma original pela equação:

$$
Y=A+B(X-P)-|X-P|)
$$

e na forma adaptada pela equação $Y=A-B$ $(X-P+|X-P|)$, em que $Y$ representa a estimativa da variável em questão; | representa módulo; A representa a produtividade máxima (patamar superior); B é a metade do ângulo formado entre a projeção do patamar de produtividade máxima com a reta inclinada (ascendente ou descendente); e P é o valor de $\mathrm{X}$ quando a curva muda bruscamente seu comportamento. As características positivas deste modelo são a boa representação do patamar de produtividade máxima e a fácil visualização do valor do coeficiente $P$, que, nesse caso, representa a estimativa direta do PAI. 


\section{RESULTADOS E DISCUSSÃO}

A densidade de infestação de E. heterophylla cresce de forma diretamente proporcional ao período de convivência da cultura com as plantas daninhas até 26 DAE (Tabela 1). A partir de $33 \mathrm{DAE}$, a densidade tende a se estabilizar, o que se relaciona à restrição da chegada de luz ao solo e conseqüente redução na germinação de E. heterophylla. No entanto, de forma semelhante ao observado por Meschede et al. (2002), o acúmulo de matéria seca das plantas daninhas (Tabela 1) continua a crescer mesmo após a estabilização da densidade, o que reflete o fato de que, embora a germinação da planta daninha tenha sido restringida depois de determinada fase do ciclo da cultura, as plantas que haviam se estabelecido tiveram sucesso no seu crescimento. A matéria seca acumulada pelas plantas daninhas possui correlação significativa e inversamente proporcional a todas as variáveis avaliadas na soja (altura, número de hastes/planta, estande final e produtividade), demonstrando tratar-se de uma variável mais importante do que a avaliação da população de infestantes (Tabela 2). Assim, o acúmulo total de matéria seca da comunidade infestante pode ser considerado um indicador mais fidedigno do que a população de plantas daninhas no que se refere ao grau de interferência imposto à cultura, o que se assemelha a resultados obtidos em outros trabalhos, em diferentes combinações de culturas e nível de infestação (Kuva et al., 2001; Melo et al., 2001; Souza et al., 2001; Freitas et al., 2002; Kozlowski et al., 2002; Salgado et al., 2002).

A Figura 2 expressa a equação que descreve a variação do estande da soja em função dos períodos crescentes de convivência com as plantas daninhas. Embora esteja claro que a interferência começa a afetar significativamente o estande entre 10 e $20 \mathrm{DAE}$, utilizando a equação ajustada pelo modelo logístico, não é possivel determinar com precisão o final do patamar inicial de máximo estande. Utilizando como exemplo uma redução aceitável de no máximo $5 \%$ do estande, obter-se-ia um valor de 17 dias para o PAI em relação a esta variável. O critério de determinar um valor percentual para definir os períodos de interferência é usual e difundido em outros trabalhos dessa natureza (Kuva et al., 2001; Melo et al., 2001;
Barreyro \& Sánchez Vallduvi, 2002; Freitas et al., 2002; Salgado et al., 2002). O parâmetro "c c" da equação indica o ponto de inflexão da curva ajustada, significando que por volta de 21 DAE já havia se estabelecido um nivel de interferência suficiente para causar $50 \%$ do total das perdas em termos de estande da cultura (Figura 2).

Não houve efeito significativo nos diferentes periodos de convivência tanto para o número de hastes / planta quanto para a altura de plantas de soja (Tabela 3).

Tabela 1 - Número de capinas realizado, densidade e matéria seca de plantas daninhas obtidas para diferentes períodos de convívio dessas com a cultura da soja, cv. BRS-133. Quarto Centenário-PR, 1999/2000

\begin{tabular}{|c|c|c|c|}
\hline $\begin{array}{c}\text { Períodos de } \\
\text { convívio com } \\
\text { plantas daninhas }{ }^{\underline{1}}\end{array}$ & $\begin{array}{l}\text { Número } \\
\text { de } \\
\text { capinas }\end{array}$ & $\begin{array}{c}\text { Densidade } \\
\left(\text { plantas } \mathrm{m}^{-2}\right)\end{array}$ & $\begin{array}{c}\text { Matéria } \\
\text { seca } \\
\left(\mathrm{g} \mathrm{m}^{-2}\right)\end{array}$ \\
\hline $0-5$ & 10 & 8 & 1,2 \\
\hline $0-12$ & 9 & 16 & 16,2 \\
\hline $0-19$ & 8 & 31 & 22,3 \\
\hline $0-26$ & 7 & 37 & 30,2 \\
\hline $0-33$ & 6 & 43 & 31,2 \\
\hline $0-40$ & 5 & 46 & 46,5 \\
\hline $0-47$ & 4 & 41 & 48,4 \\
\hline $0-54$ & 3 & 47 & 49,7 \\
\hline $0-61$ & 2 & 49 & 51,8 \\
\hline $0-68$ & 1 & 42 & 52,6 \\
\hline $0-118$ & 0 & 40 & 72,4 \\
\hline
\end{tabular}

${ }^{1 /}$ Dias após a emergência.

Tabela 2 - Estimativa do coeficiente de correlação entre variáveis relacionadas à cultura e às plantas daninhas, sob efeito dos períodos iniciais crescentes na presença destas plantas na cultura da soja, cv. BRS-133. Quarto Centenário-PR, 1999/2000

\begin{tabular}{|l|c|c|c|c|c|}
\hline Variável & Estpd & Altsoja & Hastsoja & Estsoja & Prodsoja \\
\hline Mspd & $0,76^{* *}$ & $-0,34^{*}$ & $-0,50^{*}$ & $-0,58^{*}$ & $-0,72^{* *}$ \\
\hdashline Estpd & & $-0,25$ & $-0,43$ & $-0,35$ & $-0,53$ \\
\hline Altsoja & & & 0,21 & 0,31 & 0,43 \\
\hline Hastsoja & & & & $0,45^{*}$ & $0,42^{*}$ \\
\hline Estsoja & & & & & $-0,35$ \\
\hline
\end{tabular}

mspd - matéria seca de plantas daninhas $\left(\mathrm{g} \mathrm{m}^{-2}\right)$; estpd - número de plantas daninhas $\mathrm{m}^{-2}$; altsoja - altura de plantas de soja $(\mathrm{cm})$; hastsoja - número de hastes por planta de soja; estsoja - estande de soja (número de plantas $\left.3 \mathrm{~m}^{-1}\right)$; prodsoja - produtividade da cultura $\left(\mathrm{kg} \mathrm{ha}^{-1}\right)$. 


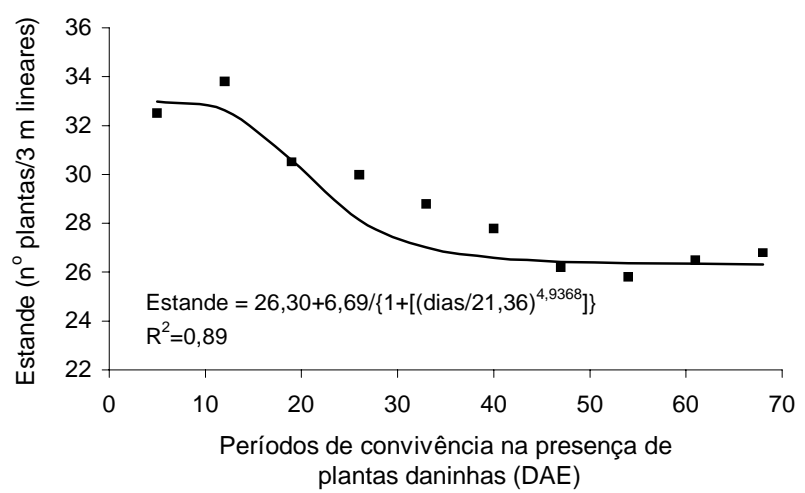

Figura 2 - Estande da soja, cv. BRS-133, em função de períodos iniciais crescentes na presença de plantas daninhas - Quarto Centenário-PR, 1999/2000.

A produtividade da soja foi significativamente afetada pelo período de interferência de E. heterophylla (Tabela 3). Pela equação ajustada, observa-se que o valor de $\mathrm{x}$ (dias), onde a curva muda bruscamente de comportamento ocorre aos 10,57 dias (Figura 3). Do ponto de vista de discussão dos dados, considerar-se-á este valor como sendo igual a 11 DAE. Dessa forma, depreende-se que a cultura pôde conviver com as plantas daninhas até 11 dias sem que estas interferissem na produtividade. No entanto, após os 11 dias de convivência, as plantas daninhas promoveram reduções na produtividade da cultura de forma linear até 68 DAE. Nesse período, cada dia de convivência das plantas daninhas com a soja representou uma perda de $6,45 \mathrm{~kg} \mathrm{ha}^{-1} \mathrm{em}$ termos de produtividade. A convivência das plantas daninhas por todo o ciclo da cultura implicou uma perda de produtividade da ordem de $38,4 \%$, segundo o modelo ajustado. Esse fato indica uma suscetibilidade mais precoce da cultura à interferência imposta por $E$. heterophylla, quando a cultura é conduzida com a densidade estabelecida neste trabalho. Sob condições usuais de densidade de plantas, os períodos anteriores à interferência (PAI) da maioria dos trabalhos situa-se entre 20 e 50 dias após a emergência (Rossi, 1985; Harris \& Ritter, 1987; Spadotto et al., 1994; Carvalho \& Velini, 2001).

Meschede et al. (2002), em experimento conduzido simultaneamente ao apresentado neste trabalho, sob as mesmas condições edafoclimáticas e de infestação da área, mas utilizando uma testemunha por repetição e quatro repetições, encontraram um PAI de 17,24 dias ao ajustar os dados também pelo modelo de Broken-Stick. Com a utilização das

Tabela 3 - Efeito de diferentes períodos de convivência das plantas daninhas com a soja sobre estande, altura, número de hastes por planta e produtividade da cultura obtidos por ocasião da colheita - Quarto Centenário, PR, 1999/2000

\begin{tabular}{|c|c|c|c|c|c|c|c|c|}
\hline \multirow[t]{2}{*}{ Período } & \multicolumn{2}{|c|}{$\begin{array}{c}\text { Estande } \\
\left(\mathrm{n}^{\mathrm{o}} \text { plantas } 3 \mathrm{~m}^{-1}\right)\end{array}$} & \multicolumn{2}{|c|}{$\begin{array}{c}\text { Altura } \\
(\mathrm{cm})\end{array}$} & \multicolumn{2}{|c|}{$\mathrm{N}^{\mathrm{o}}$ de hastes planta ${ }^{-1}$} & \multicolumn{2}{|c|}{$\begin{array}{l}\text { Produtividade } \\
\quad\left(\mathrm{kg} \mathrm{ha}^{-1}\right)\end{array}$} \\
\hline & Mato & Média TD $^{1}$ & Mato & Média TD & Mato & Média TD & Mato & Média TD \\
\hline $0-5$ & 32,50 & 32,50 & 57,45 & 59,70 & 4,60 & 5,52 & 3351 & 3443 \\
\hline $0-12$ & 33,75 & 31,25 & 59,82 & 57,22 & 4,62 & 5,65 & 3370 & 3441 \\
\hline $0-19$ & 30,50 & 34,00 & 59,72 & 57,85 & 4,77 & 4,77 & 3191 & 3515 \\
\hline $0-26$ & 30,00 & 32,25 & 57,07 & 57,77 & 4,32 & 4,65 & 3247 & 3625 \\
\hline $0-33$ & 28,75 & 33,50 & 54,77 & 59,35 & 4,30 & 4,52 & 3111 & 3553 \\
\hline $0-40$ & 27,75 & 32,75 & 56,02 & 59,52 & 4,20 & 4,52 & 2937 & 3417 \\
\hline $0-47$ & 26,25 & 31,00 & 52,47 & 57,42 & 4,12 & 4,50 & 2820 & 3391 \\
\hline $0-54$ & 25,75 & 34,75 & 57,67 & 60,72 & 4,17 & 4,17 & 2790 & 3374 \\
\hline $0-61$ & 26,50 & 35,00 & 55,85 & 58,67 & 4,02 & 4,02 & 2771 & 3425 \\
\hline $0-68$ & 26,75 & 34,20 & 53,05 & 60,75 & 4,00 & 4,00 & 2672 & 3472 \\
\hline $0-118$ & 25,00 & 31,00 & 55,25 & 58,05 & 3,95 & 4,35 & 2480 & 3531 \\
\hline F Período & $4,24 *$ & & $2,89^{\text {ns }}$ & & $1,08^{\mathrm{ns}}$ & & $9,66^{*}$ & \\
\hline $\mathrm{CV}(\%)$ & 11,70 & & 5,17 & & 8,03 & & 5,55 & \\
\hline
\end{tabular}

* Significativo a $5 \%$ de probabilidade; ${ }^{\text {ns }}$ Não-significativo a $5 \%$ de probabilidade.

$\mathrm{TD}=$ testemunhas duplas. 


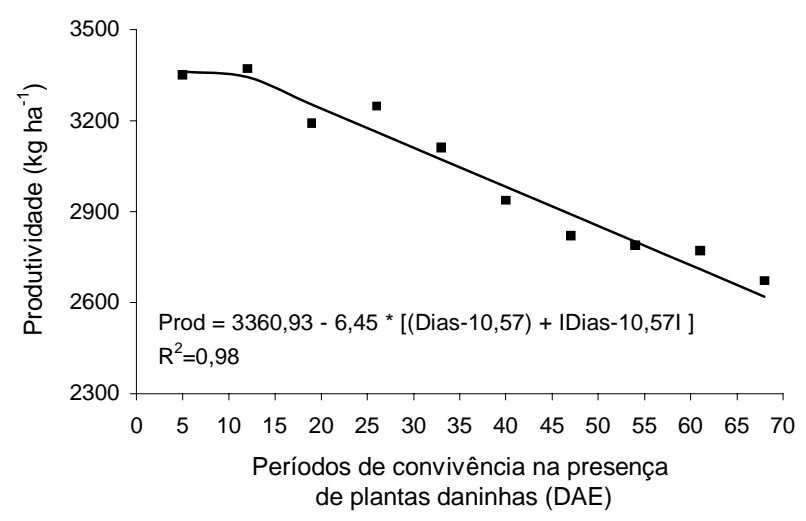

Figura 3 - Produtividade de soja, cv. BRS-133, em função de períodos iniciais crescentes na presença de plantas daninhas - Quarto Centenário-PR, 1999/2000.

testemunhas duplas e da análise por covariância, chegou-se a um valor de 10,57 dias para o PAI (Figura 3). A comparação entre os dois valores de PAI resulta numa diferença prática de seis dias em termos de necessidade de início de controle da infestação. É possivel que o controle local mais efetivo imposto pelas testemunhas duplas tenha contribuído para o controle da variabilidade do meio, repercutindo na redução do coeficiente de variação e em menores valores de DMS. A conseqüência prática é que o modelo ajustado se torna mais apto a discriminar pequenos decréscimos na produtividade.

A relevância dos dados apresentados prende-se ao fato de que a maioria dos tratamentos aplicados em pós-emergência é efetivada no período de 12 a 25 dias após a emergência. A variação na época de controle ocorre em função do sistema de semeadura utilizado (direta/ convencional), da efetividade da operação do manejo das plantas daninhas em semeadura direta e dos herbicidas, da infestação da área e das doses utilizados no controle pós-emergente. De qualquer forma, nas condições observadas neste experimento, a adoção de estratégias tradicionais de controle em pósemergência das plantas daninhas implicaria perdas na produtividade da cultura.

Esse fato sinaliza a necessidade de se iniciar mais cedo o controle das plantas daninhas na cultura da soja, principalmente sob condições de baixa densidade de plantas da cultura, sob pena de ocorrer reduções na produtividade ao se retardar o controle. Os resultados obtidos indicam, também, a necessidade de se planejar criteriosamente e com cuidado a instalação e avaliação de ensaios de matointerferência, para que maiores prejuizos sejam evitados. Assim, por uma questão de segurança, o sistema de testemunhas duplas, apesar de trabalhoso, parece adequado para a melhoria do controle local relacionado à infestação desuniforme das plantas daninhas em experimentos de campo.

O estande e a produtividade foram as variáveis que expressaram os maiores prejuízos em relação ao aumento do período de interferência das plantas daninhas. O período anterior à interferência foi de 11 dias após a emergência, com testemunhas duplas e uma infestação média de 25 plantas $\mathrm{m}^{-2}$ de E. heterophylla.

A interferência imposta pelas plantas daninhas entre 11 e 68 DAE provocou uma queda diária de $6,45 \mathrm{~kg} \mathrm{ha}^{-1}$ na produtividade da soja, com redução média de $38 \%$ da produtividade.

\section{LITERATURA CITADA}

ADEGAS, F. S. Manejo integrado de plantas daninhas em plantio direto. In: SEMINÁRIO NACIONAL SOBRE MANEJO E CONTROLE DE PLANTAS DANINHAS EM PLANTIO DIRETO, 1998, Passo Fundo. Resumo de palestras. Passo Fundo, RS: Aldeia Norte, 1998. p. 17-26.

BARREYRO, R. A.; SÁNCHEZ VALLDUVI, G. E. Delimitacion del periodo critico de competencia de malezas en cultivo de lino (Linum usitatissinum). Planta Daninha, v. 20, n. 3, p. 399-403, 2002.

BRIGHENTI, A. M. et al. Estudo preliminar da arquitetura de plantas de soja em cultivares de ciclo precoce e semiprecoce. In: REUNIÃO DE PESQUISA DE SOJA DA REGIÃO CENTRAL DO BRASIL, 2000, Cuiabá. Anais... Londrina: EMBRAPA - CNPSo, 2000. v. 22. p. 180.

CARVALHO, F. T.; VELINI, E. D. Períodos de interferência de plantas daninhas na cultura da soja. I - cultivar IAC-11. Planta Daninha, v. 19, n. 3, p. 317-322, 2001.

CHRISTOFFOLETI, P. J.; PASSINI, T. Modelagem nas interações plantas daninhas x plantas cultivadas. In: CONGRESSO BRASILEIRO DA CIÊNCIA DAS PLANTAS DANINHAS, 22., 2000, Foz do Iguaçu. Palestras. Londrina: Sociedade Brasileira da Ciencia das Plantas Daninhas, 2000. p. 1-24.

Planta Daninha, Viçosa-MG, v.22, n.2, p.239-246, 2004 
COLWELL, J. D.; SUHET, A. R.; RAIJ, B. van. Statistical procedures for developing general soil fertility models for variable regions. Australia: CSIRO, 1988. 68 p. (CSIRO, Division of Soils. Divisional Report, 93).

CONSTANTIN, J. Avaliação da seletividade do herbicida halosulfuron à cana-de-açúcar (Saccharum sp.). 1996. 65 f. Tese (Doutorado em Agonomia - Agricultura) Universidade Estadual Paulista, Botucatu, 1996.

\section{EMPRESA BRASILEIRA DE PESQUISA}

AGROPECUARIA - EMBRAPA. Tecnologias de produção da soja - região Central do Brasil - 2003. Londrina: Embrapa Soja: Embrapa Cerrados: Embrapa Agropecuária Oeste: ESALQ, 2002. 199 p. (Sistemas de produção, 1)

FAGLIARI, J. R.; OLIVEIRA JR., R. S.; CONSTANTIN, J. Nova metodologia para avaliação da seletividade de herbicidas para a cultura da cana-de-açúcar. Acta Sci., v. 24, n. 5, p. 122-123, 2002.

FREITAS, R. S. et al. Interferência de plantas daninhas na cultura do algodão em sistema de plantio direto. Planta Daninha, v. 20, n. 2, p. 197-205, 2002.

GIORDANI, G. M. R. C. et al. Seletividade de herbicidas aplicados em pré e pós-transplante da cultura da alface. Acta Sci., v. 22, n. 4, p. 985-991, 2000

HARRIS, T. C.; RITTER, R. L. Giant green foxtail (Setaria viridis) and fall panicum (Panicum dichotomiflorum) competition in soybeans (Glycine max). Weed Sci., v. 35, p. 663-668, 1987.

KOZLOWSKI, L. A. Período crítico de interferência das plantas daninhas na cultura do milho baseado na fenologia da cultura. Planta Daninha, v. 20, n. 3, p. 365-372, 2002.

KOZLOWSKI, L. A. et al. Interferência de plantas daninhas na cultura do feijoeiro comum em sistema de semeadura direta. Planta Daninha, v. 20, n. 2, p. 213-220, 2002.

KUVA, M. A. et al. Períodos de interferência das plantas daninhas na cultura da cana-de-açúcar. II - Capim-braquiária (Brachiaria decumbens). Planta Daninha, v. 19, n. 3, p. 323-330, 2001.

KUVA, M. A. et al. Períodos de interferência das plantas daninhas na cultura da cana-de-açúcar. III - Capim-braquiária (Brachiaria decumbens) e capim-colonião (Panicum maximum). Planta Daninha, v. 21, n. 1, p. 37-44, 2003.

\section{LEE, S. S. Avaliação da seletividade de herbicidas em} duas variedades de soja sob duas densidades de semeadura. 2001. 44 f. Dissertação (Mestrado em Agronomia - Produção Vegetal) - Universidade Estadual de Maringá, Maringá, 2001.

MELO, H. B. et al. Interferência das plantas daninhas na cultura da soja cultivada em dois espaçamentos entre linhas. Planta Daninha, v. 19, n. 2, p. 187-191, 2001.
MESCHEDE, D. K. et al. Período crítico de interferência de Euphorbia heterophylla na cultura da soja sob baixa densidade de semeadura. Planta Daninha, v. 20, n. 3, p. 381-387, 2002.

PITELLI, R. A. et al. Efeito de períodos de controle de plantas daninhas na cultura do amendoim. Planta Daninha, v. 20, n. 3, p. 389-398, 2002.

RATKOWSKY, D. A. Handbook of nonlinear regression models. New York: Marcel Dekker, 1990. 241 p.

ROSSI, C. A. Efeitos de períodos de controle e de convivência das plantas daninhas na cultura da soja. Jaboticabal, UNESP, 1985. 49 p. (Trabalho de graduação)

SALGADO, T. P. et al. Períodos de interferência das plantas daninhas na cultura do algodoeiro (Gossypium hirsutum). Planta Daninha, v. 20, n. 3, p. 373-380, 2002.

SKÓRA NETO, F. Uso de caracteres fenológicos do milho como indicadores do início de interferência causada por plantas daninhas. Planta Daninha, v. 21, n. 1, p. 81-87, 2003.

SOUZA, J. R. P.; MACHADO, J. R.; VELINI, E. D. Crescimento de Brachiaria plantaginea e Rapahanus raphanistrum em convivência com híbridos de milho submetidos a períodos de controle das plantas daninhas. Planta Daninha, v. 19, n. 2, p. 209-215, 2001.

SPADOTTO, C. A. et al. Determinação do período crítico para prevenção da interferência de plantas daninhas na cultura da soja: uso do modelo "Broken-Stick". Planta Daninha, v. 12, n. 2, p. 59-62, 1994.

VELINI, E. D. et al. Avaliação da seletividade do clomazone, aplicado em pré ou pós-emergência, a dez variedades de canade-açúcar (cana-planta). In: CONGRESSO BRASILEIRO DA CIÊNCIA DAS PLANTAS DANINHAS, 20., 1995, Florianópolis. Resumos... Londrina: Sociedade Brasileira da Ciencia das Plantas Daninhas, 1995. p. 221-222.

VELINI, E. D. Estudo e desenvolvimento de métodos experimentais e amostrais adaptados à matologia. 1995, 198 f. Tese (Doutorado em Agronomia - Produção Vegetal) Universidade Estadual Paulista, Jaboticabal, 1995.

VELINI, E. D. Interferência entre plantas daninhas e cultivadas. In: KOGAN, M., LIRA, V. J. E. Avances en manejo de malezas en la produccion agricola y florestal. Santiago del Chile: PUC/ALAM, 1992. p. 41-58.

VOLL, E. et al. Competição relativa de espécies de plantas daninhas com a cultura da soja. Planta Daninha, v. 20, n. 1, p. 17-24, 2002. 